\section{Betrayers of trust?}

John Galloway

The Power of Life or Death: A Critique of Medical Tyranny. By Fabian Tassano. Duckworth: 1995. Pp. 177. £12.95 (pbk).

Wrong Medicine: Doctors, Patients and Futile Treatment. By Lawrence I. Schneiderman and Nancy S. Jecker. Johns Hopkins University Press: 1995. Pp. 200. \$25.95, £21.50.

THE trouble with medicine is that it has shifted from magic and mystery to science and technology without society, including the medical profession, quite realizing this fact. Science in the guise of medical technology now gives medicine considerable power over people's lives, including their deaths. Yet it still seems that medical training involves an initiation into arcane mysteries rather than learning practical and technical skills and judging if and when to use them. Society accords doctors a considerable moral authority not necessarily granted to other professionals. The powerful concept of clinical freedom has its roots here with its implication that doctors are never wrong - at worst only negligent.

When medicine was largely ineffectual, this hardly mattered. The trouble started when science began to make medicine work. Serious moral and economic issues arise when one really can prolong or 'save' someone's life rather than letting nature take its course. At this point, matters of 'freedom' and 'choice' shift to a real agenda. Because this agenda includes the question of resources, which never seem sufficient to meet the demand or need for them, it raises the interesting conflict between collective and individual rights and the implications for doctors' ethical codes. Who should make decisions about life or death and on what grounds? These two books attempt to deal with these questions.

Fabian Tassano, an economist based in the United Kingdom, is concerned that doctors make decisions about life and death that they have no right to be making. He condemns both medicine's monopoly and its paternalism, as typified by the attitude of "I'm a doctor and I know best". He argues that statutory selfregulation of the medical profession, which ostensibly protects the public, in fact protects the monopoly.

The author shows clearly how society buttresses the view of doctors as moral arbiters and the gate-keepers of health care - and so of health; there is, for instance, a marked tendency for courts to favour doctors' views rather than those of patients and their families when differences of opinion arise over a decision to prolong or end life. Indeed, Tassano seems to be a strong follower of George Bernard Shaw, who believed that "All professions are a conspiracy against the laity".

At the core of the book, however, is Tassano's support of the rights of the individual. He believes that doctors lean towards a collectivist morality that puts us all individually at risk. He argues strongly that doctors owe a duty only to individual patients and that concerns about the public interest are at best irrelevant and at worst downright dangerous. He thinks that notions of equity are misplaced. Because equity of access to care is at the forefront of the UK National Health Service, he has no truck with it. If a patient wants treatment and can pay for it, then Tassano sees no reason why the patient should not get it.

His view goes straight to the medical jugular. Is medicine after all just a commodity, like baked beans or cars, subject only to the laws, morals and ethical codes of the marketplace? Are doctors' claims to be 'special' just a good marketing ploy? Undeniably there is a strong profit motive in medicine, and rackets are certainly in evidence, as alluded to in the book by Lawrence Schneiderman, a doctor, and Nancy Jecker, an ethicist. One feature of medicine in the marketplace raised by these US authors is that, in common with other markets, what is on offer may be worthless. The old habit of not questioning a form of treatment may give rise to the illusion that the treatment works. That science makes for effective medicine is sometimes true, but not always. Even when it works, medical science may create more problems than it solves. Medical science is slow to recognize what is demonstrably wrong or to accept what has been proved right. Why do doctors continue to give futile treatments? Do they find it impossible to admit they are powerless to help? Is the treatment simply symbolic as the authors suggest? And do patients collude with doctors in their expectations of 'a pill for every ill'? (Science itself is hardly blameless here, with its continuous stream of well-publicized 'breakthroughs'.)

Extreme cases reveal underlying principles most clearly. Both books are littered with examples of the moral, emotional and financial thickets ensnaring life-and-death decisions. Should medicine help you if the treatment will cause you intense suffering and is unlikely to cure you? Should the choice be yours? Should a baby with spina bifida be helped to live briefly, be allowed to die or even be killed? If the baby is likely to die very soon in considerable pain, would it not be better for that time to be as short as possible and for the death to be controlled? How does the parents' suffering enter the equation? How important are their views? If you wish to end your life, should a doctor help you? Should someone in a coma with irreparable brain damage be kept physiologically alive and, if so, for how long?

Science does not come with instructions on use; it has forced medicine and society to face the fact that decisions about life and death have to be made, but says nothing about who should make them. Surely this is a question for society and its individual members. Doctors and patients must all be well informed about care and its consequences and their views must be based on the best possible information. We seem to have got as far as the idea of evidence-based medicine. Let's go all the way and have evidence-based patient choice.

John Galloway is at the Eastman Dental Institute and Hospital for Oral Health Sciences, 256 Gray's Inn Road, London WC1X 8LD, UK.

Dictionary digest
Latin Names Explained: A Guide to the
Scientific Classification of Reptiles,
Birds and Mammals by A. F. Gotch.
Cassell, $£ 20$. "A mine of information and
illumination to naturalists who have
used these names for years without
understanding their import", wrote
Nature's reviewer of an earlier
edition.

Ainsworth and Bisby's Dictionary of the Fungi by D. L. Hawksworth, P. M. Kirk, B. C. Sutton and D. N. Pegler (8th edn). CAB International, $\$ 49.95, £ 30$.

Contains some 20,000 entries, covering all fungal generic names and terms, biographical notes, information on metabolites and mycotoxins and broad accounts of pure and applied aspects of the subject. Rich pickings for professional and amateur mycologists alike.

The Concise Oxford Dictionary of Ecology edited by Michael Allaby. Oxford University Press, $£ 7.99$ (pbk). Contains 5,000 entries derived from the Oxford Dictionary of Natural History. Includes biographical notes on important figures in the subject.

The Concise Oxford Dictionary of Earth Sciences edited by Ailsa Allaby and Michael Allaby. OUP, $£ 8.99$ (pbk). Nature's reviewer marvelled at "how the editors have compressed so much so clearly... a feat which occurs only once in a blue moon - and even that is defined!".

\section{Correction}

In Irving M. Klotz's review of Nazi Science by Mark Walker (Nature $\mathbf{3 7 9}$, 410; 1996), the Von Weizsacker referred to should have been Carl Friedrich, not Ernst (his father and Nazi Minister of State). The mistake was made in the editorial office of Nature. Our apologies. 